\title{
Edu-Cloud: On-the-fly Employability Skills as a Service
}

\author{
Sonia Shahzadi ${ }^{1}$, Muddesar Iqbal ${ }^{2}$, Tasos Dagiuklas $^{2}$ \\ ${ }^{1}$ Swan Mesh Networks Ltd \\ ${ }^{2}$ London South Bank University, UK \\ Emails: s.shahzadi@swanmesh.com, \{m.iqbal,tdagiuklas $\} @ 1$ lsbu.ac.uk \\ handling of IPR, confidentiality and trust and conflict resolution.
}

\begin{abstract}
Century global job market competition requires Science, Technology, Engineering and Mathematics (STEM) university curricula to support both state-of-the-art technical and soft skills learning to improve graduate employment. This necessitates the transformation of the current teaching and learning methodology powered by a social and collaborative platform to provide a social co-learning environment. This social co-learning will provide students with opportunities for self-enrichment while supporting their technical skills and hands-on needs. The platform must also provide the required lab infrastructure for hands-on experimentation. This paper proposes the design and implementation of a cloud based platform called Edu-Cloud. The Edu-Cloud has been designed to provide automated resource provisioning and perform on-the-fly deployment of scalable virtual network functions to stream multimedia content closer to the global learners. This would help to meet the specific learning needs of a group of global interconnected students with similar learning skills and abilities. The benchmarking performance results show that the proposed framework works efficiently while reducing primary network traffic by deploying resources closer to the users and support scalability for a global deployment scenario.
\end{abstract}

Keywords-Mobile Edge Computing, Cloud, Skills as a Service, STEM.

\section{INTRODUCTION}

There are eight skills that can be defined as Employability Skills [35]. These skills include Communication, Teamwork, Problem Solving, Initiative and Enterprise, Planning and Organising, Self-Management, Learning and Technology and are secor agnostic. Traditionally these skills are not incorporated into the curricula taught in Science, Technology, Engineering and Mathematics (STEM) Universities [1]. The course content development is not student led. The students usually are not involved on the development of contents or execution of courses, which in most cases, are instructor driven using a traditional non-interactive teaching methodology. Traditional classroom activities hardly provide any opportunities to students for peer learning or access to external professional experts and mentors from relevant industry. Thus, resulting in a wider skill gap between what students are being exposed to on-campus and what global market and industrial organizations expect from them. Teaching soft skills in STEM Universities is another challenging issue in developing countries due to lack of sufficient ICT infrastructure and availability of suitable instructors to teach these skills [2].

Yet, another challenge faced by engineering and technology students in Higher Educational Institutions is the availability of suitable physical lab infrastructures, this is particularly an issue for institutions who wish to engage their students in applied and practical experimentation $[1,3,4,5]$. This is due to the fact that such infrastructure is quite expensive for STEM curricula.

Additionally, interconnecting different labs and experimental platforms belonging to different administrative domains mean granting access to remote resources that are owned by different stakeholders. This requires a legal framework to be in place to govern these relations and which must include among others:
In terms of content, a wide variety of online educational and skills videos are freely available to students through social media sites such as YouTube [6], Daily motion [7] and Vimeo [8]. MOOCs (Massive Open Online Course) are continually being created and uploaded by world class institutes such as Harvard [9] and MIT [10] on social media sites and professional websites such as Coursera. Many individual who have expertise in their field are also contribute to online learning videos such as Khan Academy [11], Time4Learning [12], Codecademy [13] and Udemy [14]. Despite having millions of educational videos available on a single topic, the existing virtual learning environments are failing to substitute the real-time classroom learning experience for students. This is because the current contents are being offered to the students using a one-way noninteractive broadcast. Students are overwhelmed with options and can spend considerable amounts of time on searching and wondering but not learning.

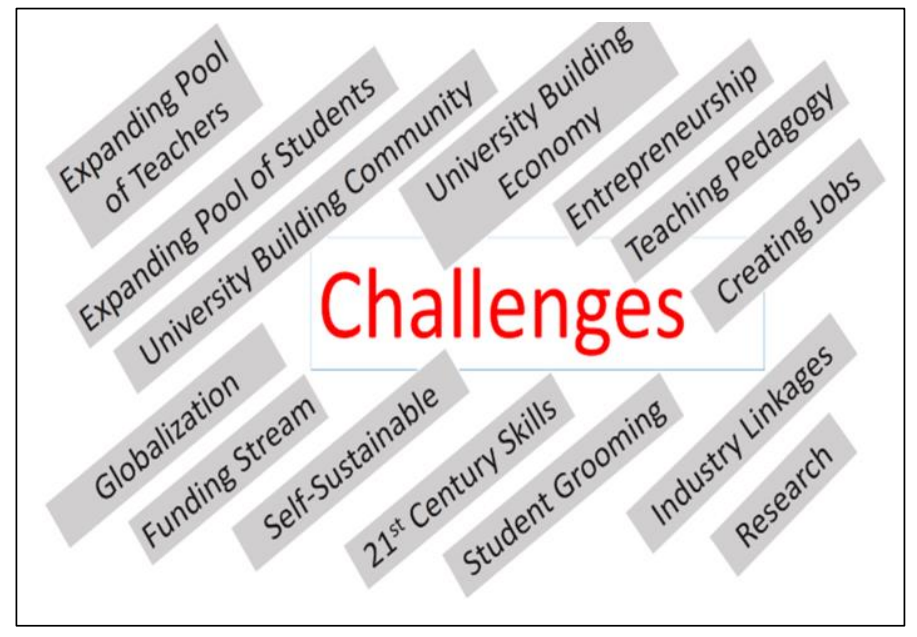

Fig. 1. $21^{\text {st }}$ Century Challenges faced by HEIs

Figure 1 expresses the challenges faced by Higher Education Institutes (HEIs) in the 21st century. In order to address these challenges, HEIs need to provide students with a social and collaborative platform that can help them to develop their full potential. A platform which promotes positive youth development through blended learning, coaching and mentoring of essential life skills, leadership and soft skills for career development and self-enrichment [15]. A platform is needed to support backend technology to facilitate social collaboration and broadcast the contents to provide employability skills as a service. The content has to be tailored to the specific learning needs of a particular group of students in a globally connected social co-learning environment

In [6], a system and method is originally invented for creating and managing a social network based channel to schedule and manage channel contents according to a user's contextual information available via social network. The inventor also proposed to incorporate different charging strategies that charge a user, and give a user incentives and apply a penalty in return of 
special actions performed by the user.

In this paper, the design and implementation of a cloud based platform and service called Edu-Cloud is presented. The Educloud provides a social co-learning environment and broadcast multimedia educational contents to meet the specific learning needs of a group of students with similar learning skills and abilities.

The Edu-Cloud multimedia contents will benefit from the live feedback from the users to meet specific learning needs of students. This is accomplished by allowing the students to rate the content and recommend the content to a wider student community with similar interests. The platform will quickly adapt available contents to student learning patterns and preferences based on the live feedback from mentors, facilitators, and co-learners. This learner driven, social colearning environment will enable students to not only learn from the recorded contents and live mentoring sessions but also from fellow students in a globally connected social co-learning environment. The remainder of this paper is structured as follows. Section II presents state of the art. Section III describes use cases that are relevant to our proposed solution. Section IV presents the methodology of our proposed framework. Section $\mathrm{V}$ describes the test-bed implementation. Section VI describes the evaluation of results with the experimental setup. While section VII conclude this paper and gives future direction.

\section{ONLINE EDUCATION AND LEARNING}

Educational games have been introduced to education since they combine problem-solving, with higher order thinking [16, $17,18,19]$. The rate of educational transformation as in teaching and learning affordances is also rapidly accelerating. Students learn formally as well as informally through blended learning, MOOCs, Webinars, and online training courses as well as Ubiquitous teaching and learning activities, across a variety of platforms with heterogeneous capabilities [19, 20, 21]. The pace of technological change is faster than ever before. In today's world, the change could arise in months, weeks, days, or even minutes. Technology-enhanced learning is now feasible through augmented reality enablers over our smartphones and tablets.

It has been estimated that nearly $50 \%$ of subject knowledge acquired during the first year of a four year technical degree is outdated by the time the student graduates. Consequently, there is a need to provide a bundle of specific tools, skillset and resources that will guide and assist the present-day educator and assist in engaging todays learners. The Augmented Reality cognitive learning platform allowing end-users to experience virtual environments. This can be used as an essential tool to train STEM students to complex and real-life conditions [22]. Mobile/Augmented technologies potentially equip learners with tools that know how and what should be learned. It will also help students to understand social media and help them access relevant communities and societies, fellow students, and experts that can assist and guide them to undergo cognitive and visual learning. The use of Ubiquitous and Seamless Learning bonds private and public learning spaces, learning occurs through both individual and collective energies, and across different time spans, as well as different contexts (such as in-school vs. after-school, formal vs. informal learning, physical world vs. virtual reality and cyberspace).

Mobile-Augmented Learning through Game Based Instruction could act as a catalyst, empowering effective pedagogies through facilitating engagement, deep content understanding, freedom of learning from space and time barriers, interactive learning techniques, authentic and autonomous instruction conditions, situated cognition, constant efficient collaboration and a permanent link between classroom experiences and the actual life [23].

There are many commercial and open source platforms that are available for on-line learning. All of them, have difficulty in order to embed and integrate external tools that are important to drive hands-on experience and provide collaborations within a virtualized distributed learning lab environment.

Cloud computing is an emerging technology which is being used to support many applications in health care [33], smart cities [32], agriculture [34] and disaster management [24]. - In [27], development and implementation of e-learning system are given to fulfil the needs of educational institutions. VisCa, a dashboard system that show the learning status of the user to improve the learning activities and services [28]. Adaptive learning and recommendation platform (ALR) is proposed in [29], to build a conceptual map of adaptive learning and educational recommender for each individual student. A Ubiquitous eTeaching \& eLearning (UTiLearn) has been presented in [30], to enhance the teaching and learning management. An existing platform also called EduCloud is proposed in [31]. A comparative analysis was presented in table 1 .

Cloud computing backed data centers can provide scalable and on-demand shared resources. The Edu-Cloud is designed to automate resource provisioning and perform on-the-fly deployment of scalable virtual network functions to broadcast educational content closer to the learners based on the real-time user scenario for interactive co- learning for globally connected students. These virtual network functions support multimedia educational content broadcast and also offers on-demand computing resource-provisioning on-the-fly to support the required quality of experience for the end user based on their feedback. Furthermore, resource provisioning may also facilitate to deploy physical lab infrastructure based on the technical needs of students. In the second phase of this project, Future work is planned to incorporate social media network resources to provide them with the social co-learning environment. Such platform creates challenging requirements; those cannot be satisfied using a classical cloud computing paradigm. This requires the use of latest cloud technologies including Mobile Multi-Access Edge Computing and on-the-fly virtual network functions deployment. These technologies can ensure the required Quality of Experience (QoE) through dynamic resources provisioning for different use-cases while supporting collaboration among globally located mentors and co-learners around the multimedia educational contents. 
Table I: Comparison of existing e-learning platforms with proposed solution

\begin{tabular}{|c|c|c|c|c|c|c|c|c|c|c|}
\hline System & $\begin{array}{l}\text { Black } \\
\text { board }\end{array}$ & $\begin{array}{l}\text { Code } \\
\text { Acad } \\
\text { emy }\end{array}$ & $\begin{array}{l}\text { Cours } \\
\text { er } \\
\text { a }\end{array}$ & EdX & Moodle & TED ED & $\begin{array}{l}\text { Udacit } \\
\mathbf{y}\end{array}$ & Udemy & $\begin{array}{l}\text { Existing } \\
\text { Edu- } \\
\text { Cloud }\end{array}$ & $\begin{array}{l}\text { Propose } \\
\text { d Edu- } \\
\text { Cloud }\end{array}$ \\
\hline Certificate & $\mathrm{Y}$ & $\mathrm{N}$ & $\mathrm{Y}$ & $\mathrm{Y}$ & $\mathrm{N}$ & $\mathrm{N}$ & $\mathrm{Y}$ & $\mathrm{N}$ & $\mathrm{N}$ & $\mathrm{N}$ \\
\hline $\begin{array}{l}\text { Infrastructure } \\
\text { Awareness }\end{array}$ & N/A & N/A & N/A & N/A & N/A & N/A & N/A & N/A & $\mathrm{N}$ & $\mathrm{Y}$ \\
\hline Open Source & $\mathrm{N}$ & $\mathrm{N}$ & $\mathrm{N}$ & $\mathrm{Y}$ & $\mathrm{Y}$ & $\mathrm{Y}$ & $\mathrm{N}$ & $\mathrm{N}$ & $\mathrm{Y}$ & $\mathrm{Y}$ \\
\hline $\begin{array}{l}\text { User } \\
\text { Preference } \\
\text { Awareness } \\
\end{array}$ & N/A & N/A & N/A & N/A & N/A & N/A & N/A & N/A & $\mathrm{N}$ & Y \\
\hline Media Types & $\begin{array}{l}\text { Video } \\
\text { Audio } \\
\text { Slides }\end{array}$ & $\begin{array}{l}\text { Flash } \\
\text { and } \\
\text { Editor } \\
\mathrm{s}\end{array}$ & $\begin{array}{l}\text { Video } \\
\text { and } \\
\text { Slides }\end{array}$ & $\begin{array}{l}\text { Video } \\
\text { and } \\
\text { Slides }\end{array}$ & $\begin{array}{l}\text { Video, } \\
\text { Audio }\end{array}$ & $\begin{array}{l}\text { Video- } \\
\text { Animatio } \\
\mathrm{n}\end{array}$ & $\begin{array}{l}\text { Video } \\
\text { and } \\
\text { Slides }\end{array}$ & Video & N/A & $\begin{array}{l}\text { Video, } \\
\text { Audio, } \\
\text { Slides }\end{array}$ \\
\hline Pre Requisite & $\begin{array}{l}\text { May } \\
\text { or } \\
\text { may } \\
\text { not }\end{array}$ & $\mathrm{N}$ & $\mathrm{N}$ & $\mathrm{N}$ & $\mathrm{N}$ & $\mathrm{N}$ & $\mathrm{N}$ & $\mathrm{N}$ & N/A & $\mathrm{N}$ \\
\hline $\begin{array}{l}\text { Programming } \\
\text { Language }\end{array}$ & $\begin{array}{l}\text { ASP, } \\
\text { Other } \\
\mathrm{s}\end{array}$ & $\begin{array}{l}\text { HTM } \\
\text { L, JS, } \\
\text { PHP }\end{array}$ & $\begin{array}{l}\mathrm{C} \\
\text { Langu } \\
\text { age }\end{array}$ & $\begin{array}{l}\text { Python, } \\
\text { JavaScri } \\
\text { pt, Ruby }\end{array}$ & $\begin{array}{l}\text { PHP, } \\
\text { HTML, } \\
\text { Js }\end{array}$ & $\begin{array}{l}\text { HTML, } \\
\text { JavaScri } \\
\text { pt }\end{array}$ & Python & $\begin{array}{l}\text { HTML, } \\
\text { JS, } \\
\text { PHP }\end{array}$ & Python & Python \\
\hline $\begin{array}{l}\text { Progress } \\
\text { Tracking }\end{array}$ & $\mathrm{Y}$ & $\mathrm{N}$ & $\mathrm{Y}$ & $\mathrm{Y}$ & $\mathrm{N}$ & $\mathrm{N}$ & $\mathrm{Y}$ & $\mathrm{N}$ & N/A & $\mathrm{Y}$ \\
\hline $\begin{array}{l}\text { Student } \\
\text { Forum }\end{array}$ & Y & $\mathrm{Y}$ & $\mathrm{N}$ & $\mathrm{N}$ & $\mathrm{N}$ & $\mathrm{Y}$ & $\mathrm{N}$ & $\mathrm{N}$ & N/A & Y \\
\hline Time Slotted & Y & $\mathrm{N}$ & $\mathrm{Y}$ & $\mathrm{Y}$ & $\mathrm{N}$ & $\mathrm{N}$ & $\mathrm{N}$ & $\mathrm{N}$ & N/A & $\mathrm{Y}$ \\
\hline Video hosting & $\begin{array}{l}\text { Client } \\
\text { Server } \\
\mathrm{s}\end{array}$ & $\begin{array}{l}\text { No } \\
\text { Video } \\
\mathrm{s}\end{array}$ & $\begin{array}{l}\text { Privat } \\
\text { e } \\
\text { Server } \\
\text { s }\end{array}$ & YouTube & $\mathrm{N}$ & YouTube & $\begin{array}{l}\text { YouTu } \\
\text { be }\end{array}$ & $\begin{array}{l}\text { Private } \\
\text { Servers }\end{array}$ & $\begin{array}{l}\text { Private } \\
\text { Cloud } \\
\text { Server }\end{array}$ & $\begin{array}{l}\text { Cloud } \\
\text { Servers }\end{array}$ \\
\hline $\begin{array}{l}\text { User } \\
\text { Evaluation }\end{array}$ & $\mathrm{Y}$ & $\mathrm{Y}$ & N/A & N/A & N/A & $\mathrm{Y}$ & N/A & N/A & N/A & $\mathrm{Y}$ \\
\hline $\begin{array}{l}\text { QoE based } \\
\text { Resource } \\
\text { Provisioning }\end{array}$ & N/A & N/A & N/A & N/A & N/A & N/A & N/A & N/A & $\mathrm{N}$ & $\mathrm{Y}$ \\
\hline $\begin{array}{l}\text { Mentors and } \\
\text { Co-learners } \\
\text { Feedback } \\
\text { Integration }\end{array}$ & N/A & N/A & N/A & N/A & N/A & N/A & N/A & N/A & $\mathrm{N}$ & $\mathrm{Y}$ \\
\hline $\begin{array}{l}\text { Edge } \\
\text { Controller }\end{array}$ & N/A & N/A & N/A & N/A & N/A & N/A & N/A & $\begin{array}{l}\text { Not } \\
\text { availabl } \\
\text { e }\end{array}$ & $\mathrm{N}$ & Y \\
\hline
\end{tabular}




\section{EDU-CLOUD PLATFORM USE-CASES}

To provide a global social co-learning environment for students, multimedia educational contents require live feeds to improve and customize them based on the learning needs of globally connected co-learners. The contents can be further improved and moderated by a pool of mentors and facilitators with professional and industrial experience. Use cases requiring on-demand virtual network functions deployment was contemplated in an on-demand fashion closer to the end user while other requires smart strategies to incorporate new learning pedagogy to make the most of the available multi-media educational contents in the social co-learning environment.

\section{1) Use case 1}

As usage of the web and social applications grow rapidly, Edu-Cloud will collaborate with these applications to get responses, shares, comments, likes and dislikes etc. Thus, the Edu-Cloud will provide personalized, learner driven, techenabled social co-learning environment to students, where they can leverage, validate, collaborate, communicate and synthesize existing and new multimedia educational content to help each other learn better. Figure 2 illustrates use case in a visual form.

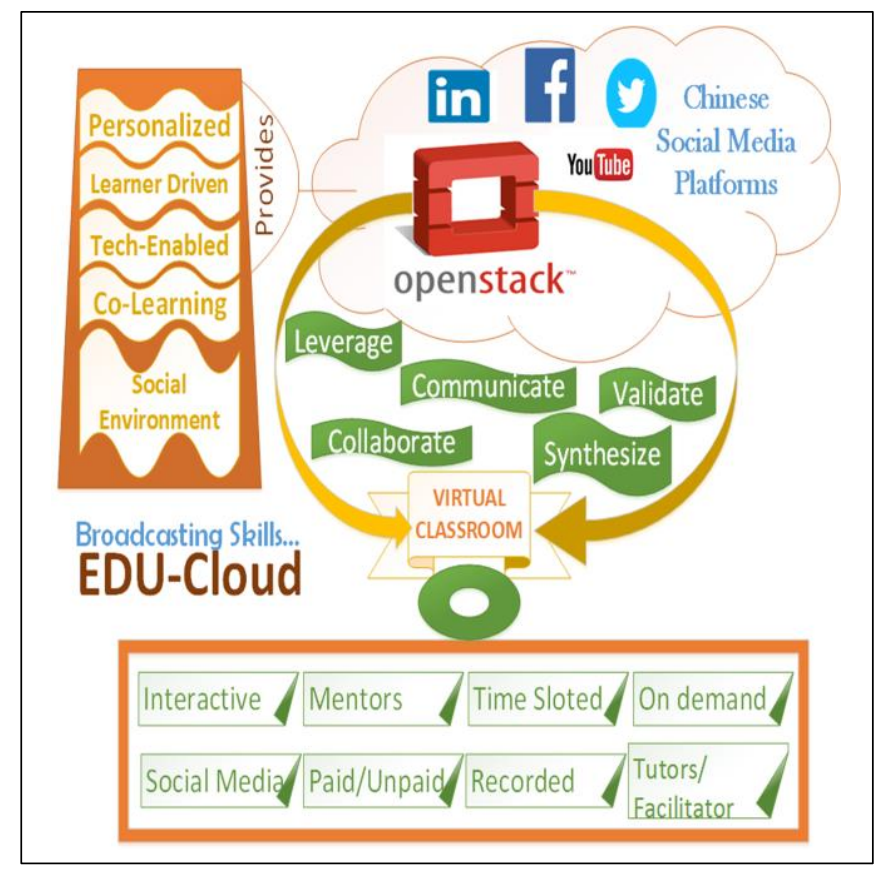

Fig. 2 Edu-Cloud Scenarios for Distributed Applications

\section{2) Use case 2}

The Edu-Cloud can embed commercial virtual testbeds (e.g. Cisco Learning Labs, OMNET, ns-3) so that both learners and instructors that are geographically distributed to participate in a virtual classroom can use it. The main Controller is responsible for managing distant connections from multi-tenant clouds as well as the connection requests from external users to execute certain simulation tasks. In order to standardize the architecture, all platforms (i.e., hardware or software simulators, algorithms, etc.) are encapsulated within Edu-Cloud as virtual network functions. These modules are geographically distributed across multi-tenant clouds and run on different platforms with various and unequal execution capabilities, which prevent any natural synchronous behaviour. Therefore, commands and information exchange are supported by events containing information in parameters. The Module may send, receive and process events.

\section{PROPOSED EDU-CLOUD FRAMEWORK}

The paper presents a conceptual model of this framework and implemented a proof of concept test-bed. It supports scalability and capable of fault-tolerance as well as reduce the congestion of core network traffic to the main/central cloud. Previously, the team has proposed and implemented a Hyper Text Transfer Protocol-based rate adaptive transcoding and streaming technique that maintains its multimedia streaming quality, especially when the network grows congested [24]. In the proposed testbed, we have used these pre-configured Multimedia Streaming virtual machine images have been used to create and deploy on-the-fly virtual network functions using the proposed algorithms closer to the end users to reduce latency. Each edge controller is dynamically reconfigurable and can easily interact with any geographically distributed cloud. The integration and implementation of Social Networks are beyond the scope of this paper, which has been planned for the future work.

\section{A. Edu-Cloud Architecture}

A cloud computing platform can be deployed using geographically distributed physical machines called compute nodes connected to the single controller and the network node. Therefore, the 3-tier architecture of OpenStack cloud with Controller, Compute and Network nodes have been used to deploy Infrastructure as Service for the proposed Edu-Cloud. In order to emulate a distributed cloud environment, multiple compute nodes have been used using different physical machines. Though both the machines have been deployed in the same location but during production, each compute node may be deployed in a different geographical location closer to the user based on the number of users in each region and computing requirements to serve them. Figure 3, shows the high-level view of the proposed architecture. Controller, compute and network nodes are implemented for OpenStack deployment [25].

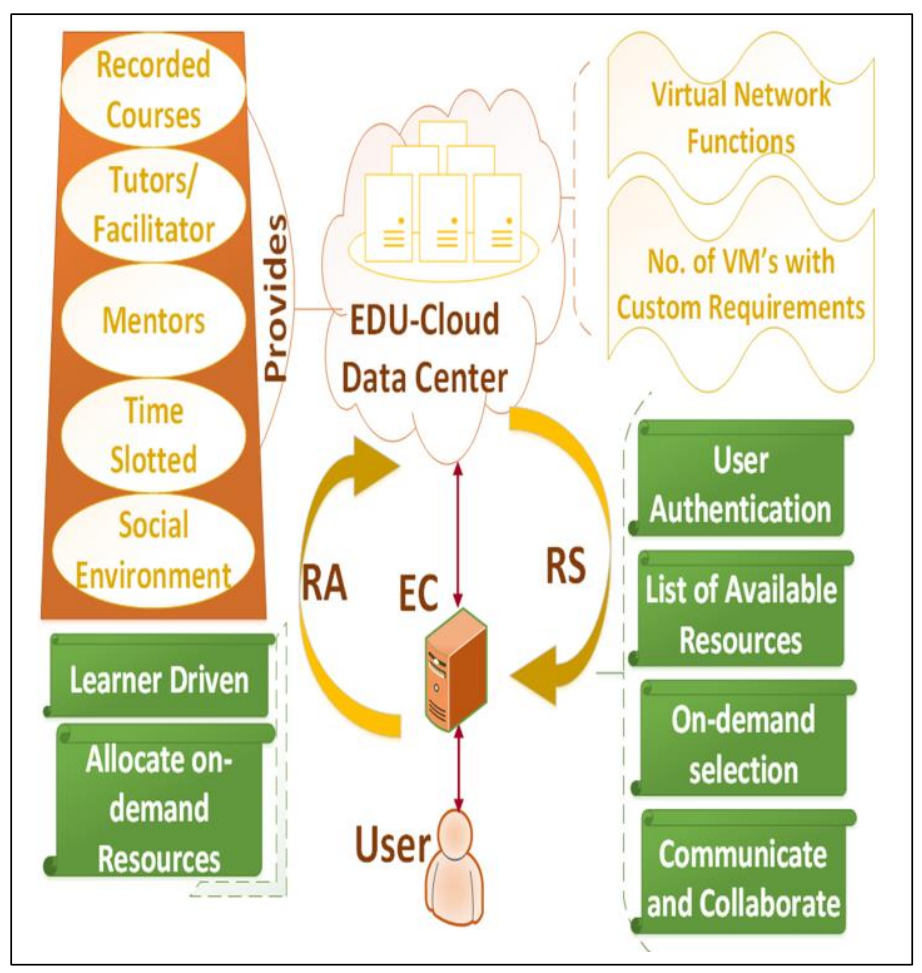


Fig. 3 High-Level view of Proposed Edu-Cloud Architecture

- Resource Provisioning: Edu-Cloud Provisioning Algorithm (ECPA) has been designed and developed, to perform resource provisioning in order to deploy new or upgrade existing virtual network functions to facilitate edu-cloud applications. This is achieved by developing an API, which automates the deployment of Edu-Cloud resources based on the QoE feedback from the user. The algorithm is divided into two following components:

- Resource Selector (RS): RS selects the resources based on the end user feedback to facilitate the required QoE. RS maintains a record of all the available cloud resources to the user, including application images, flavors, available processing, memory and storage. The algorithm will select the desired resources from the server based on the end user QoE feedback. After necessary verifications and validations, the RS pass on the information to the RA to deploy or upgrade the virtual network functions closer to the user at the edge of the network.

- Resource Allocator (RA): Once, the RS has completed its processing to select the required resources, the RA deploys/upgrade the virtual network functions to the specified location to closer to the user in order to facilitate the required $\mathrm{QoE}$ for the end user. This task is performed by the Edge controller, which is designed to offload the resources closer to the end user in order to minimize the latency and improve the performance for all the applications. In case, the algorithm enters a wrong service selection, then RS generates an error message.

The Edu-Cloud Provisioning Algorithm (ECPA) algorithm is designed to intelligently select and allocate the resources. Let suppose that a set of resources indexed by $\mathrm{i}$ and defined functions as $\mathrm{RS}(\mathrm{i}), \mathrm{RA}(\mathrm{i})$ and $\mathrm{AV}(\mathrm{i})$ that are representing Resource Selection, Resource Allocation, and Available Resources on cloud respectively. The resource provisioning is based on the ECPA algorithm. According to ECPA,

$$
\mathrm{A}(\mathrm{x})= \begin{cases}\mathrm{AV}(i)-\operatorname{RS}(i) & \text { if } \operatorname{RS}(i) \leq \mathrm{AV}(i) \\ \mathrm{AV}(i) & \text { if } \operatorname{AV}(i)<\operatorname{RS}(i) \\ 0 & \text { otherwise. }\end{cases}
$$

The RS keeps record of requested resources and validates the conditions and then RA may allocate resources accordingly.

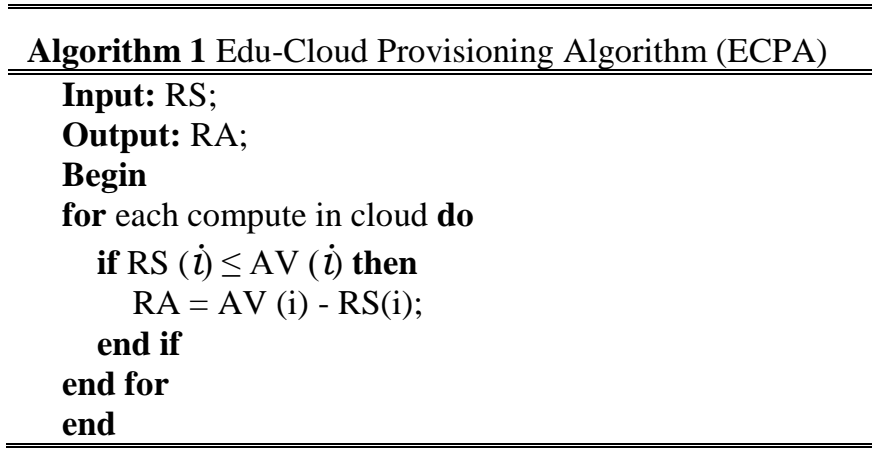

\section{IMPLEMENTATION}

As shown in the figure 4 , a cloud testbed have been developed using open-source cloud platforms where EdgeController (EC) is used to deploy the cloud resources closer to the user. Openstack infrastructure have been used to provide Infrastructure as a Service (IaaS), The Python based Libcloud API has been used to develop and implement ECPA algorithm which not only launches virtual network functions but also automates resource provisioning for Edu-Cloud on the fly using native OpenStack APIs for the following services.

- Edu-Cloud Compute System: It provides computing services for the management of compute instance lifecycle. This service provides instances/servers with different flavors of instances that are predefined in terms of memory, CPU and storage. These instances can be tiny, small, medium, large and xlarge.

- Edu-Cloud Networking System: It provides networking services between cloud components and also provides external networking connectivity to the users.

- Edu-Cloud Authentication System: It offers identity services and not only provides authorization and authentication for users but also for cloud services. It serves as an authentication system for the cloud. This identity service provides mainly following two functions: Tracking users and their permission and provide a catalogue of available services with their API endpoints.

- Edu-Cloud Image System: It provides image service for retrieval and storing virtual machine images. It provides a base template of Edu-Cloud where users can start a new instance.

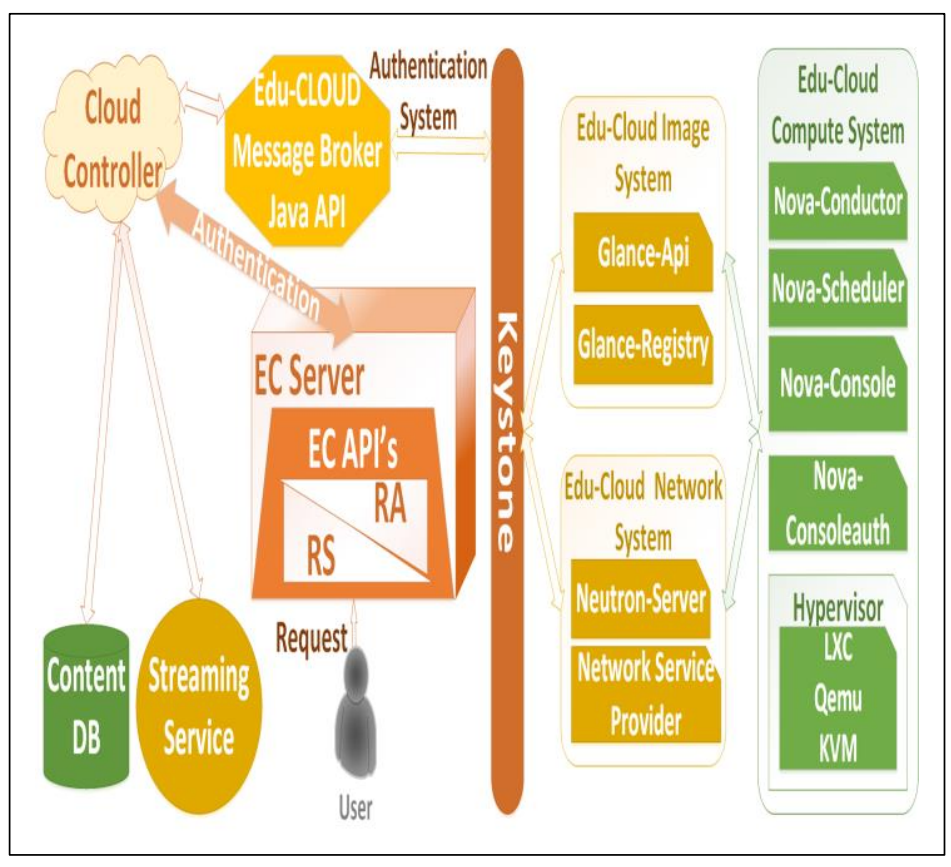

Fig. 4 Detailed Architecture of Edu-Cloud Implementation

The tools used to develop the experimental testbed are given in Table II.

TABLE II. Tools for testbed

\begin{tabular}{ll}
\hline \hline Item & Description \\
\hline \hline Cloud IaaS Platform & OpenStack \\
\hline Cloud Architecture & 3-tier \\
\hline Cloud Supported Library & LibCloud \\
\hline Host OS & Ubuntu 14.04 \\
\hline Language & Python \\
\hline \hline
\end{tabular}

\section{EVALUATION}

Rally, a tool has been used to measure Edu-Cloud scalability and performance testing. The main emphasis of the 
bench- marking is to assess how Edu-Cloud would work at a global scale. In this section, rally benchmarking has been performed to measure the scalability of Edu-Cloud and test the cloud performance. Following is the glossary of key terms used in benchmarking scenarios evaluation and discussion.

- Scenario: Scenario is the name of the input file/configuration that is used to test your cloud performance.

- Load duration (s): Load duration shows the duration of load that is produced by particular scenario.

- Full duration (s): In full duration includes overall execution time of scenario and duration for environment preparation with contexts.

- Iterations: Represent the number of iterations for each scenario.

- Runner: Specify the type of load, when its type is set constant which means the constant load is created during a fixed amount of time when the particular scenario is running.

- Errors: Show the number of unsuccessful iterations. If all iterations of your scenario are run successfully then it will show 0 error.

- Success criteria, Service-Level Agreement (SLA): SLA checks that the specific scenario has passed certain success criteria.

- Success: If all iterations of specific scenario are run successfully, then it will show a $100 \%$ success.

- Count: Show the number of iterations.

- Atomic action: Small set of atomic operations that are performed for each specific scenario.

The Edu-Cloud performance is tested using the following cases:

\section{A. User-Student Requests via Edge Controller}

To check the reliability and effectiveness of the Edu-Cloud in terms of accommodating user virtual network functions initiation requests sent via Edge Controller, certain mock number of requests have been initiated. The performance of a concurrent number of user's requests is measured when they demand resources.

In this scenario, various number of requests have been initiated with 20 iterations using the following code scenario.

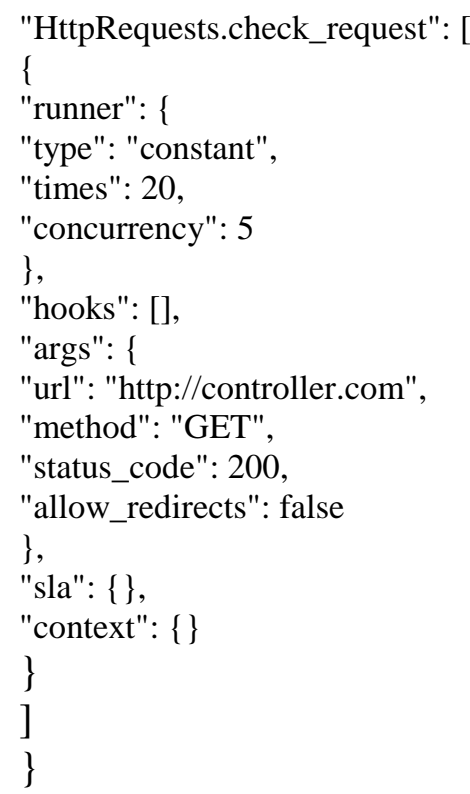

These requests have been successfully achieved in an accepted average time under 1 second as shown in the graph except from iterations 14 to 16 , the time went up to a maximum of 5.488 seconds as shown in figure 5 which is an acceptable time for given scenarios.

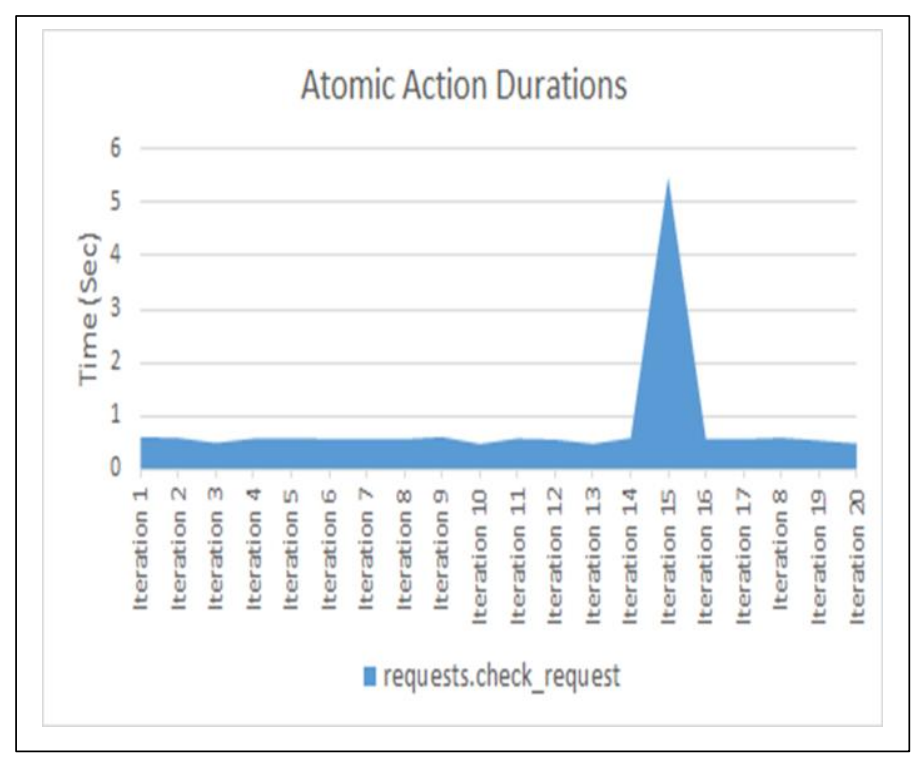

Fig. 5 Graphical illustration of the test result

\section{B. Edu-Cloud Authentication System Testing}

Several authentication tests have been performed to evaluate the following authentication service scenarios.

- Authenticate Keystone: In this scenario, Edu-Cloud keystone service has been authenticated using 100 simultaneous iterations with the following scenario code.

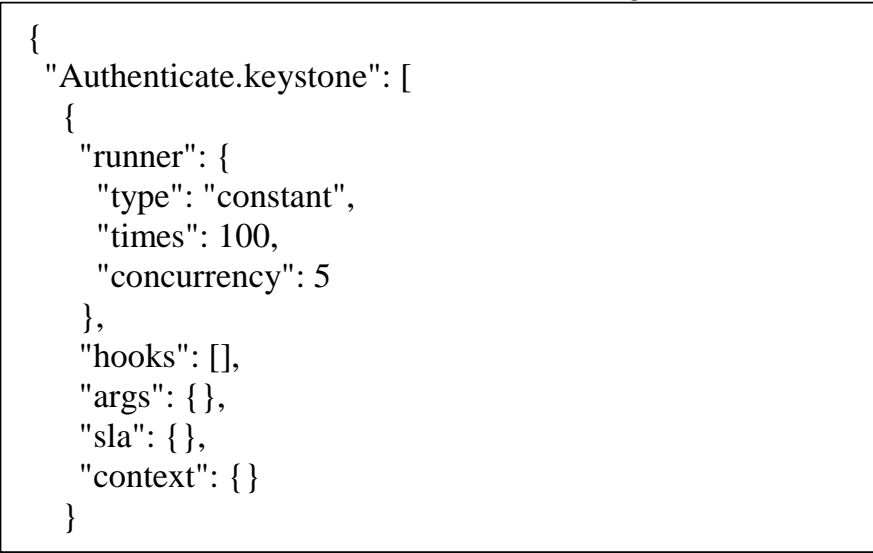

This scenario has been successfully completed in an acceptable average time bellow 0.5 seconds in most of the iterations, except only in few iterations, it went up to a maximum of 2.726 seconds as shown in figure 6 .

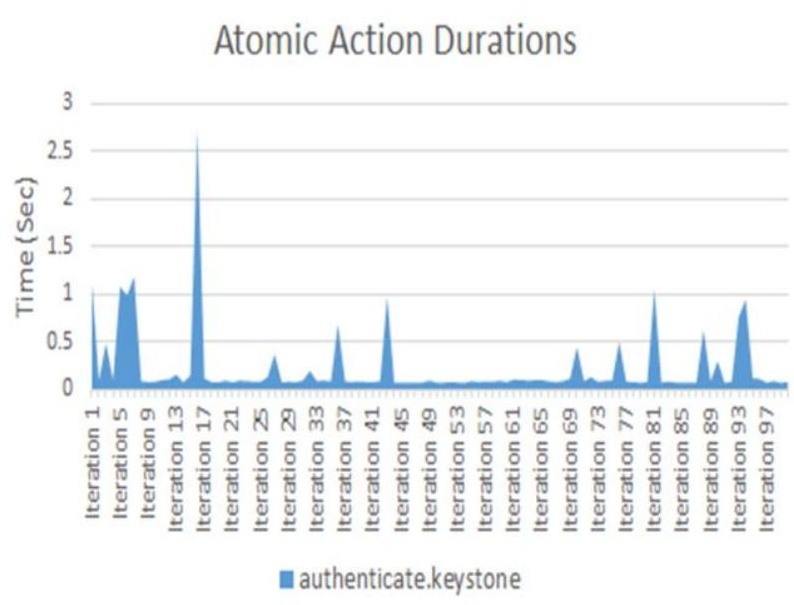


Fig. 6 Graphical illustration of the test result

- Authenticate Glance: In this scenario, Edu-Cloud Glance service has been authenticated with 10 iterations along two repetitions with the following code.

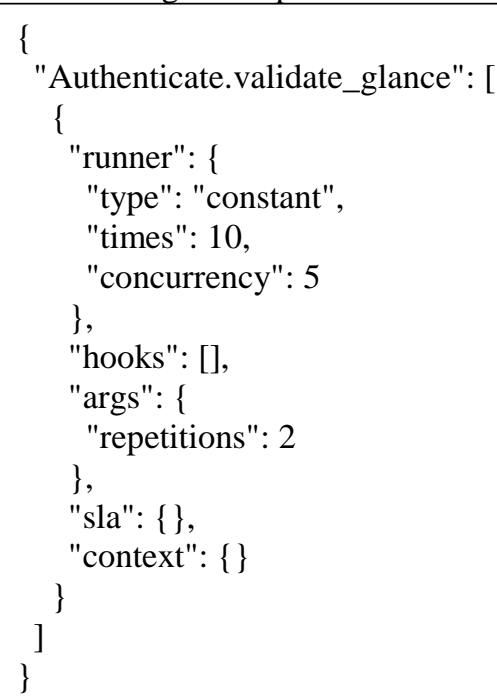

This scenario has been successfully completed in an acceptable average of 0.150 seconds in all alterations as given in figure 7 .

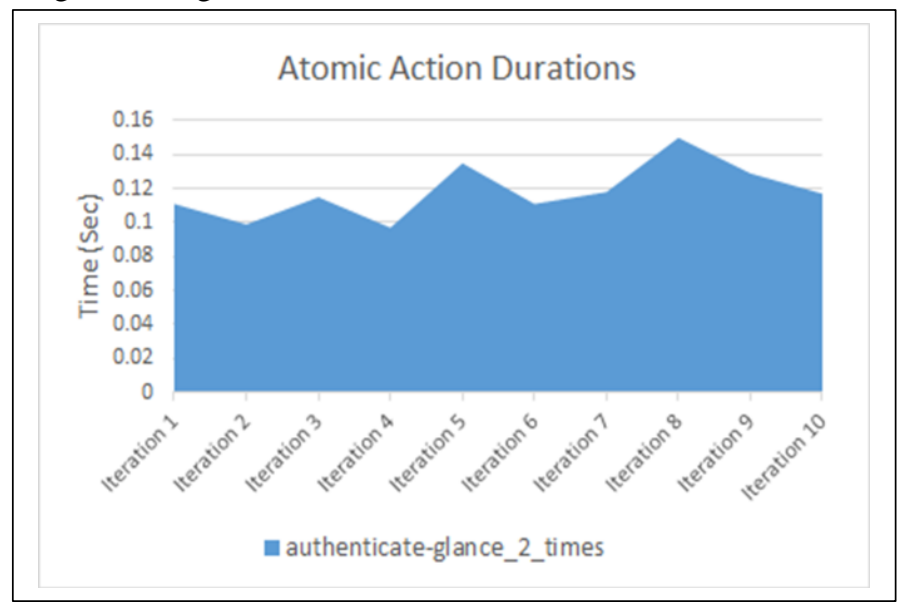

Fig. 7 Graphical illustration of the test result

- Authenticate Nova: In this scenario, Edu-Cloud Nova services have been authenticated using 10 iterations with two repetitions using the following scenario code.

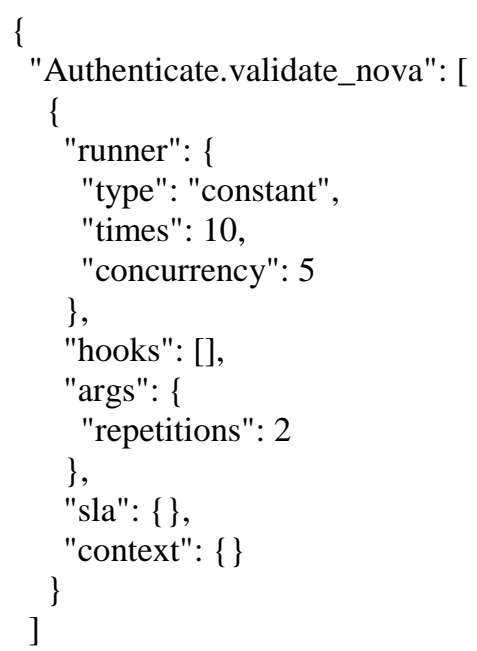

Considering the fact that the process involves creation and 
deletion of the entire VM Servers with the given pre-configured OS image, this is resource hungry process. These functions were performed to evaluate the EC resource-provisioning algorithm which initiate the Virtual Network Function upon receiving user requests. This whole scenario has been successfully completed in 84.182 seconds as given in figure 9 where each colour represents individual atomic action.

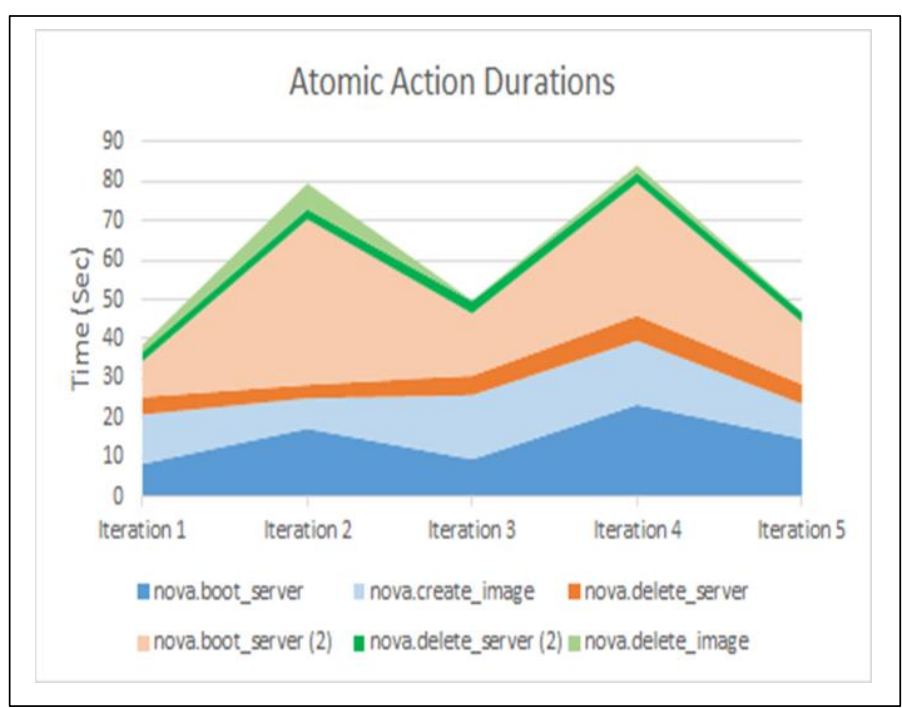

Fig. 9 Graphical illustration of the test result

Now in Section D, observations have been made on how the algorithm reacts to a bigger size, real-time, fully functional multimedia streaming server.

\section{Multimedia Streaming Virtualization Testing}

Previously, a real-time testbed was developed by the authors that can deliver high-quality streaming videos by transcoding the original video in real time to a scalable codec [17]. In this section, this multimedia streaming server image has been used with the following pre-configured tools that details are given in Table III.

Table III.

\begin{tabular}{ll}
\hline \hline Item & Description \\
\hline \hline Operating System & Linux Debian \\
\hline Hosting Application & Apache \\
\hline Transcoding & Ffmpeg \\
\hline Streaming & Apache \\
\hline Player & VLC, MX and FlowPlayer \\
\hline AB.mov & Video clip of \\
$(480 \times 360)(480 \times 360)$ & $480 \times 360480 \times 360$ \\
& resolution size that has to \\
& be streamed across the \\
& network \\
\hline CD.mov & Video clip of \\
$(640 \times 360)(640 \times 360)$ & $640 \times 360640 \times 360$ \\
& resolution size that has to \\
& be streamed across the \\
& network \\
\hline \hline
\end{tabular}

A test is planned on how ECPA algorithm will react to realtime multimedia streaming service requests. As in ECPA algorithm, RS (i) must be less than or equal to AV (i), otherwise, it will create some failed iterations due to demands for over capacity resources.

To run streaming service in Edu-Cloud, Streaming Server image flavor must use at least medium capabilities (i.e. vCPUS=2, RAM=4096 MB and Disk=40 GB).

To measure the services performance with ECPA algorithm, Overloaded resource scenarios have been run i.e. RS (i) > RA (i) with 3 iterations as given in following scenario code. Although, this scenario has been completed in 512.788 seconds but it also invalidated some actions by generating some failed iterations as expected during ECPA validation process.
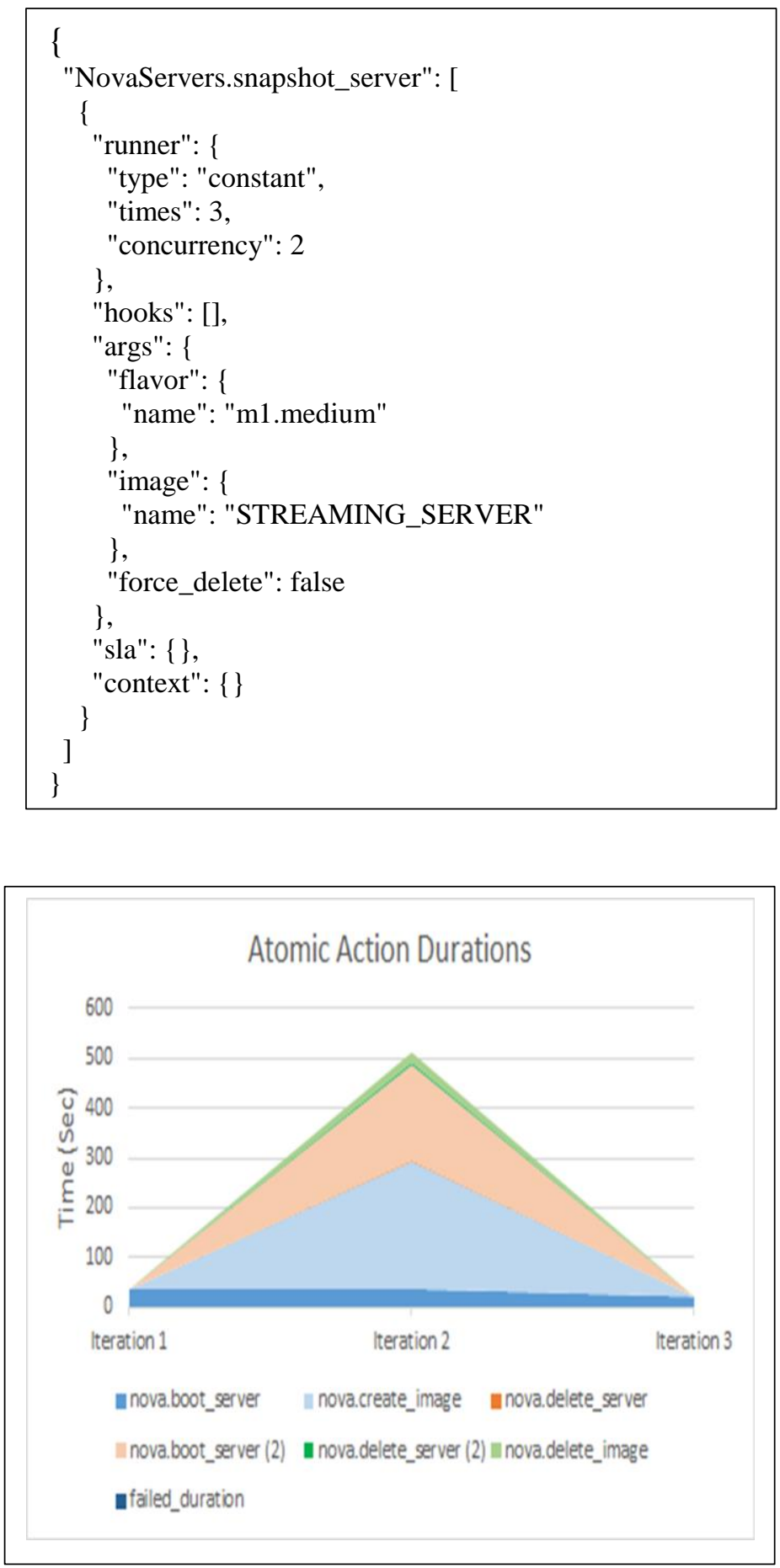

Fig. 10 Graphical illustration of the test result

The Rally benchmarking results give assurance that proposed onthe-fly resource provision mechanism performs well within the given scenario and its scalability can be envisioned by proportionately adding more geographical distributed compute nodes accruing to the number of users and workloads. 


\section{DIRECTIONS}

In this paper, an on-demand instant provisioning mechanism has been proposed that will work on the fly based on user preference in a cloud environment. A cloud testbed has been implemented using the OpenStack platform which provides IaaS to the end user. An instant provisioning algorithm is proposed and implemented using the libcloud API. It provides standardization among multiple cloud providers to help the users to efficiently manage their cloud resources. The evaluation of this proposed algorithm is based on real time use cases. This concludes that the proposed mechanism is beneficial to improve the cloud users experience in a multi-cloud environment.

The Rally benchmarking results give assurance that the proposed on-the-fly resource provision mechanism performs well within the given scenario and its scalability can be envisioned by proportionately adding more geographically distributed compute node resources accruing to the number of users and workloads.

For Future work, integration of Social Networks will be added to fully implement the proposed architecture and achieve envisioned objectives. The platform will be able to quickly adapt available contents to student learning patterns and preferences based on the live feedback from mentors, facilitators, and co-learners.

\section{ACKNOWLEDGMENT}

The present work was undertaken in the context of the "Self-OrganizatioN towards reduced cost and eNergy per bit for future Emerging radio Technologies" with contract number 734545. The project has received re-search funding from the H2020-MSCA-RISE-2016 European Framework Program.

\section{REFERENCES}

[1] M. Estela-Carbonell, A. Codina, J. Poblet-Puig, P. Pardo, M. Puigv'1, E. Pujadas, S. Valls, M. A' lvarez, E. Guaus, C. Hervada-Sala, et al., "Towards the stem knowledge homogenization of pre-university students in 21st century: Mooc: The language for engineering," in Frontiers in Education Conference (FIE), 2016 IEEE, pp. 1-5, IEEE, 2016.

[2] J. M. Ritz and S.-C. Fan, "Stem and technology education: international state-of-the-art," International Journal of Technology and Design Education, vol. 25, no. 4, pp. 429-451, 2015.

[3] K. Pyatt and R. Sims, "Virtual and physical experimentation in inquiry-based science labs: Attitudes, performance and access," Journal of Science Education and Technol- ogy, vol. 21, no. 1, pp. 133147, 2012.

[4] T. De Jong, M. C. Linn, and Z. C. Zacharia, "Physical and virtual laboratories in science and engineering education," Science, vol. 340, no. 6130, pp. 305-308, 2013.

[5] J. M. Marquez-Barja, G. Jourjon, A. Mikroyannidis,

C. Tranoris, J. Domingue, and L. A. DaSilva, "Forge: Enhancing elearning and research in ict through remote experimentation," in Global Engineering Education Con- ference (EDUCON), 2014 IEEE, pp. 1157-1163, IEEE, 2014.

[6] "YouTube." https://www.youtube.com/. Accessed: 2017-03-02.
[7] "dailymotion." http://www.dailymotion.com. Accessed: 2017-03-02.

[8] "Vimeo." https://vimeo.com/. Accessed: 2017-03-02.

[9] "Havard." https://www.harvard.edu/. Accessed: 201703- 02.

[10] "MIT." http://web.mit.edu/. Accessed: 2017-03-02.

[11] "Khanacademy." https://www.khanacademy.org/. Accessed: 2017-03-02.

[12] "Time4learning." https://www.time4learning.com/. Accessed: 2017-03-02.

[13] "Codecademy." https://www.codecademy.com/. Accessed: 2017-03-02.

[14] "Udemy." https://www.udemy.com/. Accessed: 201703- 02.

[15] W. W. Porter, C. R. Graham, K. A. Spring, and K. R. Welch, "Blended learning in higher education: Institutional adoption and implementation," Computers \& Education, vol. 75, pp. 185-195, 2014.

[16] A.-H. G. Abulrub, A. N. Attridge, and M. A. Williams, "Virtual reality in engineering education: The future of creative learning," in Global Engineering Education Conference (EDUCON), 2011 IEEE, pp. 751-757, IEEE, 2011.

[17] M. Virvou, G. Katsionis, and K. Manos, "Combining software games with education: Evaluation of its educational effectiveness," Educational Technology \& Society, vol. 8, no. 2, pp. 54-65, 2005.

[18] K. Kiili, S. de Freitas, S. Arnab, and T. Lainema, "The de- sign principles for flow experience in educational games," Procedia Computer Science, vol. 15, pp. 78-91, 2012.

[19] A. R. Artino, "Motivational beliefs and perceptions of instructional quality: Predicting satisfaction with online training," Journal of computer assisted learning, vol. 24, no. 3, pp. 260-270, 2008.

[20] M. J. Dondlinger, "Educational video game design: A review of the literature," Journal of applied educational technology, vol. 4, no. 1, pp. 21-31, 2007.

[21] G. Siemens, "Massive open online courses: Innovation in education," Open educational resources: Innovation, research and practice, vol. 5, pp. 5-15, 2013.

[22] M. E. C. Santos, A. Chen, T. Taketomi, G. Yamamoto, J. Miyazaki, and H. Kato, "Augmented reality learning experiences: Survey of prototype design and evaluation," IEEE Transactions on learning technologies, vol. 7, no. 1, pp. 38-56, 2014.

[23] J. Bacca, S. Baldiris, R. Fabregat, S. Graf, et al., "Augmented reality trends in education: a systematic review of research and applications," Journal of Educational Technology \& Society, vol. 17, no. 4, p. 133, 2014.

[24] A. R. Khan, M. Iqbal, J. Muzaffar, A. Nisar, A. Ali, I. Raza, and S. A. Hussain, "Optimized congestion aware and rate-adaptive multimedia communication for application in fragile environment during disaster management and recovery," Journal of Reliable Intelligent Environ- ments, vol. 1, no. 2-4, pp. 147-158, 2015.

[25] “OpenStack." http://openstack.org. Accessed: 2017-03- 02.

[26] Jayasena, K. P. N., and Huazhu Song. "Private Cloud with e-Learning for Resources Sharing in University Environment." E-Learning, E-Education, and Online Training: Third International Conference, eLEOT 2016, Dublin, Ireland, August 31-September 2, 2016, Revised Selected Papers. Springer International Publishing, 2017.

[27] Elsaadany, Amr, and Karim Abbas. "Development and implementation of e-learning system in smart educational environment." Information and Communication Technology, Electronics and Microelectronics (MIPRO), 
2016 39th International Convention on. IEEE, 2016.

[28] Lin, Chan-Hsien, et al. "VisCa: A Dashboard System to Visualize Learning Activities from E-learning Platforms." International Symposium on Emerging Technologies for Education. Springer, Cham, 2016.

[29] Tseng, Hsiao-Chien, et al. "Building an Online Adaptive Learning and Recommendation Platform." International Symposium on Emerging Technologies for Education. Springer, Cham, 2016.

[30] Mehmood, Rashid, et al. "UTiLearn: A Personalised Ubiquitous Teaching and Learning System for Smart Societies." IEEE Access 5 (2017): 2615-2635.

[31] Taleb, Tarik, et al. "Mobile edge computing potential in making cities smarter." IEEE Communications Magazine 55.3 (2017): 38-43.

[32] Cemim, Paolo, et al. "EduCloud: a private cloud tool for academic environments." Cloud Computing and Communications (LATINCLOUD), 2012 IEEE Latin America Conference on. IEEE, 2012.

[33] Bhatia, Munish, and Sandeep K. Sood. "Temporal informative analysis in smart-ICU monitoring: $\mathrm{m}$ healthcare perspective." Journal of medical systems 40.8 (2016): 1-15.

[34] Student, B. E. "Cloud Computing for Agriculture." International Journal of Engineering Science 10996 (2017).

[35] "Employability skills". http://www.youthcentral.vic.gov.au/jobs-careers/planningyour-career/employability-skills. Accessed: 2017- 09-19. 